\title{
Prognostic Factors of Depression in Patients With Cancer Undergoing Chemotherapy and Radiotherapy
}

\author{
Zahra Shayan ${ }^{1}$; Zahra Shahkolahi ${ }^{2}$; Niloofar Ahmadlo ${ }^{3}$; Leila Vafaee ${ }^{4}$; Leila Shayan ${ }^{5, *}$ \\ ${ }_{1}^{1}$ Department of Community Medicine, The Medical School, Shiraz University of Medical Sciences, Shiraz, IR Iran \\ 2 Department of Pediatric and Neonatal Nursing, Faculty of Nursing and Midwifery, Isfahan University of Medical Sciences, Isfahan, IR Iran \\ 3 Department of Radiation Oncology, Shiraz University of Medical Sciences, Shiraz, IR Iran \\ ${ }_{5}^{4}$ Nemazee Hospital, Shiraz University of Medical Sciences, Shiraz, IR Iran
${ }_{5}$. \\ ${ }^{5}$ Trauma Research Center, Shiraz University of Medical Sciences, Shiraz, IR Iran \\ ${ }^{*}$ Corresponding author: Leila Shayan, Trauma Research Center, Shiraz University of Medical Sciences, Shiraz, IR Iran. Tel/Fax: +98-7116254206, E-mail: shayanl_85@yahoo.com
}

Received: March 1, 2014; Accepted: April 16, 2014

\begin{abstract}
Background: Cancer is one of the chronic diseases, which increases the risk of depression. The main causes of depression among these patients are pain due to metastasis, limited social activities and disability.

Objectives: The aim of this research was to determine the prevalence of depression and relevant factors in patients with cancer referred to Shiraz Nemazee hospital for chemotherapy and radiotherapy.

Patients and Methods: This was a cross-sectional study on 260 patients with cancer. To diagnose depression, the Beck questionnaire was used. To analyze data, logistic regression was more appropriate than the univariate analysis, because it simultaneously considers the effects of each of the predictors.

Results: The prevalence of depression was $47.4 \%$. There was a statistically significant association between depression and income $(\mathrm{P}<$ $0.001)$, family history of depression ( $\mathrm{P}=0.001)$, satisfaction with her or his condition $(\mathrm{P}<0.001)$, disease duration $(\mathrm{P}<0.001)$ and education $(\mathrm{P}=0.025)$. Logistic regression revealed that the main effective factors were disease duration more than five years $(\mathrm{OR}=5.9, \mathrm{P}=0.013), \mathrm{lack}$ of satisfaction with her or his condition $(\mathrm{OR}=19.6, \mathrm{P}<0.001)$ and family history of depression $(\mathrm{OR}=2.4, \mathrm{P}=0.049)$.

Conclusions: Consultation sessions are necessary to reduce depression of patients with cancer. Since depression may reduce quality of life and reaction to treatment, curing depression may relatively reduce side effects of disease for patients to have less pain and problems.
\end{abstract}

Keywords:Depression; Prevalence; Cancer, Chemotherapy; Radiotherapy

\section{Background}

Depression is a very common disorder around the world occurred in all ages and races, both in women and men. Cancer is one of the chronic diseases, which increases the risk of depression in individual. The main causes of depression in patients with cancer are pain due to metastases, decreased social activity and disability $(1,2)$. Depression has a negative effect on quality of life, duration of hospitalization and outcome of treatment of patients with cancer. Therefore, evaluation and treatment of this disorder in these patients are very essential. In addition to common medical problems and distress, depressed person feels that he or she is ostracized by his or her family and community. Depression is known as a risk factor, which reduces survival in patients with cancer and is an important factor to reject treatment of these patients (3-6). Rajabizadeh et al. reported that the prevalence of depression in 110 patients with cancer was 67.3\% in Kerman city (7). Tavoli et al.'s study showed that the prevalence rates of depression and anxiety were 57\% and $47.2 \%$, respectively in colon and stomach cancers (8). The study of Malekian on 173 patients with cancer showed that the prevalence of depression was $32.9 \%$ and it was more common in woman aged 50 to 65 years (9). The results of Zheng's study in Shanghai with 7967 patients with cancer reported the prevalence of depression as $24.74 \%$ (10). In another study conducted by Chen and Zheng on 1400 women with breast cancer, almost $26 \%$ of them had moderate to severe depression and $13 \%$ had clinical depression 18 months after diagnosis of their disease (11). The study of So showed the prevalence of depression as $34.4 \%$ in women with breast cancer in Hong Kong (12). Nelson et al.'s study on 716 men with prostate cancer showed that after controlling the disease stage, there was a significant association between depression and use of hormone therapy, time of disease diagnosis, physical and social health and age (13). It seems that treatment of cancer, either chemotherapy or radiotherapy is effective on depression rate in patients with cancer. Pandey et al.'s study on 117 patients with cancer revealed that $23 \%$ of patients receiving chemotherapy had depression (14). Cazzaniga et al. showed that radiotherapy in patients with cancer causes depression and anxiety. Nevertheless, they stated that providing patients with information and their own satisfaction decreased anxiety and depression following

Copyright (C) 2014, Health Promotion Research Center. This is an open-access article distributed under the terms of the Creative Commons Attribution-NonCommercial 4.0 International License (http://creativecommons.org/licenses/by-nc/4.0/) which permits copy and redistribute the material just in noncommercial usages, provided the original work is properly cited. 
radiotherapy (15). Souza et al. studied 102 patients with cancer under chemotherapy and observed that $10.8 \%$ and $1.9 \%$ of them had moderate and severe depression, respectively (16). Mashhadi et al. studied 400 patients with cancer after diagnosis of malignancy and before chemotherapy or radiotherapy and reported the prevalence of depression as $26.5 \%$ (17). Therefore, due to the high prevalence of depression in patients with cancer and its effects on cancer and disease process and response to treatment, researchers suggested experts and physicians to use counseling sessions and antidepressants drug as one of the main components of treatment for patients with cancer $(18,19)$.

\section{Objectives}

The aim of this study was to examine the prevalence of depression and identify predictor variables of depression in patients with cancer undergoing chemotherapy or radiotherapy using logistic regression.

\section{Patients and Methods}

In this cross-sectional study, 260 samples were selected with a confidence level of $95 \%$, precision of $6 \%(d=1.5 p)$ and prevalence of $40 \%$ depression. Patients were those referred to chemotherapy and radiotherapy wards in Shiraz Nemazee hospital in 2007. They entered the research until the number of samples reached 260. Patients who agreed to participate in this research were selected. Data was collected using a series of forms completed during face-toface interviews. The first part of the questionnaire included demographic characteristics and medical condition and the second instrument was Persian version of the Beck depression test. Then, the questionnaire was read by the investigator and the patient could choose the best answer. If the patient was unaware of his or her disease status, the disease data was extracted from his or her records. Beck depression test is one of the most common and reliable psychological tests applicable in all classes and social environment and is not dependent on culture. In this test, different aspects of depression can be evaluated. It contains 21 items, each with four possible responses. Each response is assigned a score ranging from 0 to 3 , indicating different levels of depression symptoms. The sum of individual item scores provided a total dimensional score of depression as the outcome variable. Intensity of depression can be classified as 0-10 without depression, 11-15 borderline symptoms, 16-20 slight depression, 21-30 moderate depression, 31-40 severe depression and more than 40 as very severe depression. Scores above 15 denote depression (7). Besides, independent variables included gender, age, marital status, education, location, income status, satisfaction from her or his condition, family history of depression, type of cancer, knowledge about the disease, type of treatment and duration of cancer. Data analysis was performed using SPSS software, version 16 (SPSS Institute, Chicago, Illinois). Univariate and multivariate analysis are two famous meth- ods of statistical analysis. Univariate analysis involves a single variable while multivariate analysis involves a dependent variable and more than one independent variable. Logistic regression is one of the multivariate analyses used when the dependent variable is a dichotomy.In univariate analysis, we cannot calculate odds ratio when the independent variables are continuous, but it is possible in logistic regression. Also, the multivariate findings are more relevant due to controlling the effects of each of the predictors simultaneously. We used t-test and Chi-square test for univariate analysis. After finding significant variables, we used logistic regression to determine variables affecting depression and to obtain odds ratio. P value below 0.05 was considered as statistically significant.

\section{Results}

Totally, 260 patients with cancer referred for chemotherapy and radiotherapy in Nemazee hospital in 2007. Eleven patients (4\%) were excluded due to incomplete questionnaires. The reliability of the depression questionnaire was 0.85 using Cronbach's alpha coefficient. From 249 patients, 88 were male (35.3\%) and 161 female (64.7\%); their age ranged from 18 to 87 years with a mean \pm SD of $49.08 \pm 14.7$ years. According to classification of depression score, 85 patients (34.1\%) had normal results, 46 (18.5\%) borderline depression, 46 (18.5\%) slight depression, 52 (20.9\%) moderate depression, 15 (6\%) severe depression and five (2\%) very severe depression. Generally, a score above 15 is considered as depression. Accordingly, the prevalence of depression was $47.4 \%$. Using univariate analysis, it was found that there was a statistically significant association between depression and education ( $\mathrm{p}=$ $0.025)$, income status $(\mathrm{P}<0.001)$, family history of depression $(\mathrm{P}=0.001)$, satisfaction from his or her condition ( $\mathrm{p}$ $<0.001)$ and duration of cancer $(P=0.001)$. Nonetheless, there was not a statistically significant association between depression and gender, age, marital status, type of cancer, knowledge about the disease and type of treatment (Tables 1, 2). After entering significant variables in logistic regression model, the results showed that 70\% of cases were classified correctly as depressed and nondepressed groups, which may seem good. Besides, the results indicated that logistic regression is appropriate for data $(\mathrm{P}=0.577)$, showing that the model prediction is not significantly different from observed values. Of variables entered logistic regression, only satisfaction from his or her condition, family history of depression and duration of cancer were good predictors of depression in patients. Odds depression in patients with a family history of depression was 4.2 times more than those without family history of depression $(\mathrm{OR}=2.4, \mathrm{P}=0.05)$. Odds depression in patients with disease duration more than five years was 9.5 times higher than those with disease duration of less than one year $(\mathrm{OR}=5.9, \mathrm{p}=0.013)$. In addition, odds depression in patients who were not satisfied with the current situation was 19.6 times higher than those who were satisfied $(\mathrm{OR}=19.6, \mathrm{P}<0.001)$ (Table 3$)$. 
Shayan Z et al.

Table 1. The Prevalence of Depression by Demographic Characteristics ${ }^{a}$

\begin{tabular}{|c|c|c|c|c|}
\hline \multirow[t]{2}{*}{ Variables } & \multicolumn{2}{|c|}{ Depression } & \multirow[t]{2}{*}{ Total } & \multirow[t]{2}{*}{ P Value } \\
\hline & Yes & No & & \\
\hline Gender & & & & 0.075 \\
\hline Male & $35(39.8)$ & $53(60.2)$ & $88(100)$ & \\
\hline Female & $83(51.6)$ & $78(48.4)$ & $161(100)$ & \\
\hline Marital status & & & & 0.902 \\
\hline Single & $13(48.1)$ & $14(51.9)$ & $27(100)$ & \\
\hline Married & $96(48.0)$ & $\begin{array}{c}104 \\
(52.0)\end{array}$ & $\begin{array}{l}200 \\
(100)\end{array}$ & \\
\hline Divorced or widowed & $9(42.9)$ & $12(57.1)$ & $21(100)$ & \\
\hline Education & & & & 0.025 \\
\hline Illiterate & $27(44.3)$ & $34(55.7)$ & $61(100)$ & \\
\hline Primary & $39(63.9)$ & $22(36.1)$ & $61(100)$ & \\
\hline guidance schooling & $16(45.7)$ & $19(54.3)$ & $35(100)$ & \\
\hline High school & $20(44.4)$ & $25(55.6)$ & $45(100)$ & \\
\hline university & $15(32.6)$ & $31(67.4)$ & $46(100)$ & \\
\hline Location & & & & 0.789 \\
\hline Urban & $90(47.9)$ & $98(52.1)$ & $188(100)$ & \\
\hline Rural & $28(45.9)$ & $33(54.1)$ & $61(100)$ & \\
\hline Income status & & & & $P<0.001$ \\
\hline $\begin{array}{l}\text { Desirable or highly } \\
\text { desirable }\end{array}$ & $21(31.8)$ & $45(68.2)$ & $66(100)$ & \\
\hline Relatively desirable & $52(44.1)$ & $66(55.9)$ & 118 (100) & \\
\hline Undesirable & $42(67.7)$ & $20(32.3)$ & $62(100)$ & \\
\hline $\begin{array}{l}\text { Satisfaction from his } \\
\text { or her condition }\end{array}$ & & & & $P<0.001$ \\
\hline Completely satisfied & $20(30.8)$ & $45(69.2)$ & $65(100)$ & \\
\hline Somewhat satisfied & $67(44.7)$ & $83(53.3)$ & $150(100)$ & \\
\hline Not satisfied & $31(93.9)$ & $2(6.3)$ & $33(100)$ & \\
\hline $\begin{array}{l}\text { Family history of } \\
\text { depression }\end{array}$ & & & & 0.001 \\
\hline No & $89(42.6)$ & $120(57.4)$ & $\begin{array}{c}209 \\
(100)\end{array}$ & \\
\hline Yes & $28(71.8)$ & $11(28.2)$ & $39(100)$ & \\
\hline
\end{tabular}

Table 2. The Prevalence of Depression by Clinical and Therapeutic Variables ${ }^{a}$

\begin{tabular}{|c|c|c|c|c|}
\hline \multirow[t]{2}{*}{ Variables } & \multicolumn{2}{|c|}{ Depression } & \multirow[t]{2}{*}{ Total } & \multirow[t]{2}{*}{ P Value } \\
\hline & Yes & No & & \\
\hline Knowing The Disease & & & & 0.674 \\
\hline No & $42(45.7)$ & $50(54.3)$ & $92(100)$ & \\
\hline Yes & $76(48.4)$ & $81(51.6)$ & $157(100)$ & \\
\hline Type of Treatment & & & & 0.172 \\
\hline Chemotherapy & $5(45.5)$ & $6(54.5)$ & $11(100)$ & \\
\hline Radiotherapy & $31(38.8)$ & $49(61.3)$ & $80(100)$ & \\
\hline $\begin{array}{l}\text { Chemotherapy and } \\
\text { radiotherapy }\end{array}$ & $81(51.6)$ & $76(48.4)$ & $157(100)$ & \\
\hline Type of Cancer & & & & 0.312 \\
\hline Breast & $43(46.7)$ & $49(53.3)$ & $92(100)$ & \\
\hline Brain & $9(33.3)$ & $18(66.7)$ & $27(100)$ & \\
\hline Head and neck & $17(44.7)$ & $21(55.3)$ & $38(100)$ & \\
\hline Others & $48(52.7)$ & $43(47.3)$ & $91(100)$ & \\
\hline Duration of Cancer & & & & 0.001 \\
\hline$<1$ year & $52(39.4)$ & $80(60.6)$ & $132(100)$ & \\
\hline 1 to 5 year & $49(51.6)$ & $46(48.4)$ & $95(100)$ & \\
\hline$>5$ year & $15(83.3)$ & $3(16.7)$ & $18(100)$ & \\
\hline
\end{tabular}

Table 3. Determination of Odds Ratio of Depression Using Significant Variables

\begin{tabular}{|c|c|c|c|c|}
\hline \multirow[t]{2}{*}{ Variables } & \multirow[t]{2}{*}{$\begin{array}{l}\text { Odds } \\
\text { Ratio }\end{array}$} & \multicolumn{2}{|c|}{$\begin{array}{l}\text { 95\% Confidence } \\
\text { Interval }\end{array}$} & \multirow[t]{2}{*}{ P Value } \\
\hline & & $\begin{array}{l}\text { Lower } \\
\text { Bound }\end{array}$ & $\begin{array}{l}\text { Upper } \\
\text { Bound }\end{array}$ & \\
\hline \multicolumn{5}{|l|}{ Education } \\
\hline University $^{a}$ & 1.0 & & & \\
\hline High school & 0.9 & 0.33 & 2.38 & 0.81 \\
\hline guidance schooling & 1.2 & 0.42 & 3.30 & 0.76 \\
\hline Primary & 2.1 & 0.84 & 5.20 & 0.11 \\
\hline Illiterate & 0.7 & 0.25 & 1.69 & 0.38 \\
\hline \multicolumn{5}{|l|}{ Income status } \\
\hline $\begin{array}{l}\text { Desirable or highly desir- } \\
\text { able a }^{\text {a }}\end{array}$ & 1.0 & & & \\
\hline Relatively desirable & 1.4 & 0.65 & 2.88 & 0.4 \\
\hline Undesirable & 2.1 & 0.86 & 5.32 & 0.1 \\
\hline \multicolumn{5}{|l|}{$\begin{array}{l}\text { Satisfaction from his or } \\
\text { her condition }\end{array}$} \\
\hline Completely satisfied ${ }^{a}$ & 1.0 & & & \\
\hline Somewhat satisfied & 1.5 & 0.75 & 3.09 & 0.24 \\
\hline Not satisfied & 19.6 & 3.88 & 99.1 & 0.001 \\
\hline
\end{tabular}

\section{Family history of depres-}

sion

\begin{tabular}{lllll} 
No $^{\mathrm{a}}$ & 1.0 & & & \\
Yes & 2.4 & 0.97 & 6.1 & 0.049 \\
$\begin{array}{l}\text { Duration Of Cancer } \\
\quad<1 \text { year }^{\mathrm{a}}\end{array}$ & & & & \\
$\quad 1$ to 5 years & 1.0 & & & \\
$>$ > years & 1.4 & 0.70 & 2.53 & 0.33 \\
\hline
\end{tabular}

${ }^{\mathrm{a}}$ Reference group.

\section{Discussion}

Depression in patients with cancer is highly prevalent and can significantly affect patients' quality of life. Nowadays, prevalence of depression in patients with cancer and types of depressive syndromes are well known. Chemotherapy and radiotherapy can dramatically affect body and mind. Therefore, investigation about this topic can be a great help to treatment of depression in patients with cancer. Our purpose was to determine the prevalence of depression in patients with cancer and then to identify prognostic factors of depression using logistic regression. Chi-square and independent t-test are not modeling techniques. In case of more than one variable, multivariate analysis is preferred to univariate analysis for several reasons:1) to calculate OR when the variable is continues; 2) to determine effective variables on outcome while holding all other variables constant; 3) to control confounding variables. According to the results of this study, the prevalence of depression in patients with can- 
cer was $47.4 \%$. Based on different studies, the prevalence of depression in patients with cancer was reported as 16\% to $67 \%(7-14,17)$. Based on primary objectives of the study, factors associated with depression varied from one study to another. As our results indicated, using univariate analysis, age, gender, marital status, education, place of residence and income status were not significant prognostic factors of depression (11). Nevertheless, depression was lower in patients who were satisfied with their economic status and had higher education. These results are consistent with some studies and not consistent with some others. For example, Pandey showed that gender was the only factor affecting depression (14), but Rajabizade and Mashhadi indicated that gender was not an effective variable on depression, but age, marital status and education significantly affected depression $(7,17)$. In Nelson's study, there was an association between age and depression (13). Malekian showed no significant associations between age, gender and depression (9). Moreover, Tavoli found no significant association between depression and gender, education and marital status (8). Chen showed that marital status, low income and low quality of life were significant prognostic factors of depression. According to the results of logistic regression, there was a statistically significant association between family history of depression, satisfaction from his or her condition and depression. Depression was less in those satisfied with their own condition. Depression in patients who were aware of their illness had no statistically significant difference with other patients, but in Tavol's study this association was significant (8). We found that depression was lower in patients who had the disease for a shorter duration. Because long-term disease can cause patient's increasing pain, metastasis, grade of disease and disability; therefore, depression is higher in this group of patients. Nelson mentioned this issue (13). Zheng reported that duration of disease, stage of disease and metastasis were important factors in depression (10), but in Malekian's study, duration of disease was not associated with depression (9). Recently, the results of Souza's study showed that income, duration of disease and number of surgeries had a significant association with depression (16), which is consistent with our results. This study mentioned that type of treatment was not associated with depression. However, some reports indicated this point $(7,9)$, but So reported that difference in the amount of depression was significant between patients undergoing chemotherapy and radiotherapy (12). Miranda et al. stated that before and after one period of chemotherapy, depression was not significantly different, but those with lower depression scores showed a better response to treatment (20). Supporting patients with cancer leads to a better treatment response. In Nordin and Hopwood's studies, it was demonstrated that social support of patients was an important factor to reduce depression. Patients with cancer must cope with many aspects of their lives affected by the disease $(5,21)$.
As the results showed, $\mathrm{P}$ value was less in univariate analysis. It might be due to presence of other variables in the model. For example, income status was significant in univariate analysis but not in multivariate analysis. The major advantage of using multivariate analysis is simultaneous control of the effects of each of variables. According to the present results and previous studies, it seems important to hold counseling sessions for treatment of depression in patients with cancer. Because depression can decrease response to treatment, its treatment can increase life expectancy of patients and lessen disease complications. Therefore, patients would experience less pain and problems associated with their cancer disease. We recommend designing programs in health care centers aimed to identify depressive symptoms and perform appropriate educational interventions to motivate patients with cancer to continue their treatment courses. A limitation of this research was assessing depression with Beck questionnaire, but not psychiatrists. This was performed since Beck questionnaire was a screening tool for depression symptoms rather than a diagnostic procedure.

\section{Acknowledgements}

The authors would like to thank N. Shokrpour from the Center for Development of Clinical Research of Nemazee Hospital for their editing services and F. Hekmat and L. Ghasrodashti for data collection.

\section{Authors' Contributions}

1- acquisition of data: Leila Vafaee and Nilloofar Ahmadloo; 2- analysis and interpretation of data:Zahra and Leila Shayan; 3- drafting of the manuscript: Zahra Shahkolahi and Zahra Shayan; 4- critical revision of the manuscript for important intellectual content: Zahra Shayan; 5- statistical analysis: Zahra and Leila Shayan; 6- administrative, technical and material supports: Zahra Shayan and Zahra Shahkolahi; 7- study supervision: Zahra Shayan.

\section{Funding/Support}

This work was supported by Jahrom University of Medical Sciences, Jahrom, Fars, Islamic Republic of Iran.

\section{References}

1. Ciaramella A, Poli P. Assessment of depression among cancer patients: the role of pain, cancer type and treatment. Psychooncology. 2001;10(2):156-65.

2. Lampic C, Thurfjell E, Bergh J, Sjoden PO. Short- and long-term anxiety and depression in women recalled after breast cancer screening. Eur J Cancer. 2001;37(4):463-9.

3. Bowers L, Boyle DA. Depression in patients with advanced cancer. Clin J Oncol Nurs. 2003;7(3):281-8.

4. Gallo JJ, Armenian HK, Ford DE, Eaton WW, Khachaturian AS. Major depression and cancer: the 13-year follow-up of the Baltimore epidemiologic catchment area sample (United States). Cancer Causes Control. 2000;11(8):751-8.

5. Nordin K, Berglund G, Glimelius B, Sjoden PO. Predicting anxiety and depression among cancer patients: a clinical model. Eur J Cancer. 2001;37(3):376-84

6. Pirl WF, Siegel GI, Goode MJ, Smith MR. Depression in men receiv- 
ing androgen deprivation therapy for prostate cancer: a pilot study. Psychooncology. 2002;11(6):518-23.

7. Rajabizadeh GH, Mansoori SM, Shakibi MR, Ramazani MA Determination of Factors Related to Depression in Cancer Patients of the Oncology Ward in Kerman. J Kerman Univ Med Sci. 2005;12(2):142-7.

8. Tavoli A, Mohagheghi MA, Montazeri A, Roshan R, Tavoli Z, Omidvari S. Anxiety and depression in patients with gastrointestinal cancer: does knowledge of cancer diagnosis matter? BMC Gastroenterol. 2007;7:28.

9. Malekian A, Alizadeh A, Ahmadzadeh GH. Anxiety and Depression in Cancer Patients. J Res Behav Sci. 2007;5(2):115-8.

10. Zheng Y, Wang JJ, Zou JJ, Wu CX, Bao PP, Lu W. [Study on the prevalence of depression among cancer patients and its influencing factors in Shanghai]. Zhonghua Liu Xing Bing Xue Za Zhi. 2007;28(1):57-60.

11. Chen X, Zheng Y, Zheng W, Gu K, Chen Z, Lu W, et al. Prevalence of depression and its related factors among Chinese women with breast cancer. Acta Oncol. 2009;48(8):1128-36.

12. So WK, Marsh G, Ling WM, Leung FY, Lo JC, Yeung M, et al. Anxiety, depression and quality of life among Chinese breast cancer patients during adjuvant therapy. EurJ Oncol Nurs. 2010;14(1):17-22.

13. Nelson CJ, Weinberger MI, Balk E, Holland J, Breitbart W, Roth AJ. The chronology of distress, anxiety, and depression in older prostate cancer patients. Oncologist. 2009;14(9):891-9.
14. Pandey M, Sarita GP, Devi N, Thomas BC, Hussain BM, Krishnan R. Distress, anxiety, and depression in cancer patients undergoing chemotherapy. World J Surg Oncol. 2006;4:68.

15. Cazzaniga LF, Maroni D, Bianchi E, Bossi A, Cagna E, Cosentino D, et al. Anxiety, depression and informed consent in patients referred to a radiotherapy department. Tumori. 2003;89(2):176-82.

16. de Souza BF, Pires FH, Dewulf Nde L, Inocenti A, Silva AE, Miasso AI. [Patients on chemotherapy: depression and adherence to treatment]. Rev Esc Enferm USP. 2013;47(1):61-8.

17. Mashhadi MA, Shakiba M, Zakeri Z. Evaluation of depression in patients with cancer in South of iran (zahedan). Iran J Cancer Prev. 2013;6(1):12-6.

18. Angelino AF, Treisman GJ. Major depression and demoralization in cancer patients: diagnostic and treatment considerations. Support Care Cancer. 2001;9(5):344-9.

19. Schwartz L, Lander M, Chochinov HM. Current management of depression in cancer patients. Oncology (Williston Park). 2002;16(8):1102-10.

20. Miranda CR, de Resende CN, Melo CF, Costa AL, Jr., Friedman H. Depression before and after uterine cervix and breast cancer neoadjuvant chemotherapy. Int J Gynecol Cancer. 2002;12(6):7736.

21. Hopwood P, Stephens RJ. Depression in patients with lung cancer: prevalence and risk factors derived from quality-of-life data. JClin Oncol. 2000;18(4):893-903. 